\title{
A rare acute neck pain cause that can have misdiagnosis or missed diagnosis-crowned dens syndrome: description of two cases and a literature analysis
}

\author{
Xin Qin ${ }^{1}$, Xiaofei Hu², Qingzhen Wang ${ }^{1}$, Jigang Zeng ${ }^{1}$, Jie Chen ${ }^{1}$ \\ ${ }^{1}$ Department of Radiology, Xingyi People's Hospital, Qian Xi'Nan, Gui Zhou, China; ${ }^{2}$ Department of Radiology, Southwest Hospital, Third Military \\ Medical University, Chongqing, China
}

Correspondence to: Jie Chen. Department of Radiology, Xingyi People’s Hospital, Qian Xi’Nan, Guizhou, China. Email: 1043544766@qq.com.

Submitted Dec 12, 2020. Accepted for publication Apr 13, 2021.

doi: 10.21037 /qims-20-1347

View this article at: http://dx.doi.org/10.21037/qims-20-1347

\section{Introduction}

The crowned dens syndrome (CDS) is a rare condition that can cause acute neck pain and restricted movement. It is manifested as microcrystalline formation due to the deposition of calcium pyrophosphate dehydrate (CPPD) or calcium hydroxyapatite (HA) around the dens. On images, especially those of computed tomography (CT), it is nodular, flaky, or annular around the dens, similar to a "crown-like calcification", which is a specific imaging manifestation. Due to a lack of reports on this disease in Chinese literature, the clinical understanding of CDS is insufficient, often resulting in misdiagnosis or missed diagnosis. Herein, we have reported 2 cases of CDS with typical clinical histories and characteristic findings on CT and review the relevant literature.

\section{Case description}

\section{Case 1}

A 74-year-old woman was admitted to the hospital with a history of "acute head and neck pain for 1 week with fever". A week ago, without a clear trigger, the patient suffered from head and neck tingling pain with limited neck mobility, the pain of which was intolerable. The pain was obvious when the head and neck were in motion. She had been treated in the outpatient department of our hospital for occipital neuralgia and had experienced no significant improvement after symptomatic treatment. Her physical examination findings at admission were as follows: temperature, $37.9^{\circ} \mathrm{C}$; pulse, 70 beats/min; respiration, 19 breaths/min; blood pressure, 130/70 $\mathrm{mmHg}$. The patient's symptoms were acute pain, head and neck tenderness, and restriction of movement of the neck in all directions, including rotation. Laboratory examination findings at admission were as follows: white blood cell (WBC) count, $11.32 \times 10^{9} / \mathrm{L}$ (normal $4-10 \times 10^{9} / \mathrm{L}$ ); erythrocyte sedimentation rate (ESR) $23.6 \mathrm{~mm} / \mathrm{h}(0-20 \mathrm{~mm} / \mathrm{h})$; C-reactive protein (CRP): $55.6 \mathrm{mg} / \mathrm{L}(0-6 \mathrm{mg} / \mathrm{L})$. An unenhanced cervical spinal CT (Figure 1) showed annular high-density around the axis dens, with 183-342 HU. Annular high-density was also revealed at the dens posterior and superior aspects in sagittal and coronal multi-planar reformatting (MPR) imaging.

The combination of clinical history and CT images led to a diagnosis of CDS. Then, the patient was treated with glucocorticoids (methylprednisolone sodium succinate, $40 \mathrm{mg}$ QD, iv.gtt) and nonsteroidal anti-inflammatory drugs (NSAIDs) (diclofenac sodium, $40 \mathrm{mg}$ QD, PO). After 5 days of continuous treatment, the patients' clinical symptoms began to improve, and the symptoms were almost fully relieved on the $7^{\text {th }}$ day of admission. The WBC, ESR, hypersensitive CRP, and other indicators had also almost restored to normal by this time. The patient was followed up by telephone for 3 months, and no reappearance was noted during this period.

\section{Case 2}

A 65-year-old man was admitted to hospital due to "acute shoulder and neck pain for 4 days with slight fever". The 

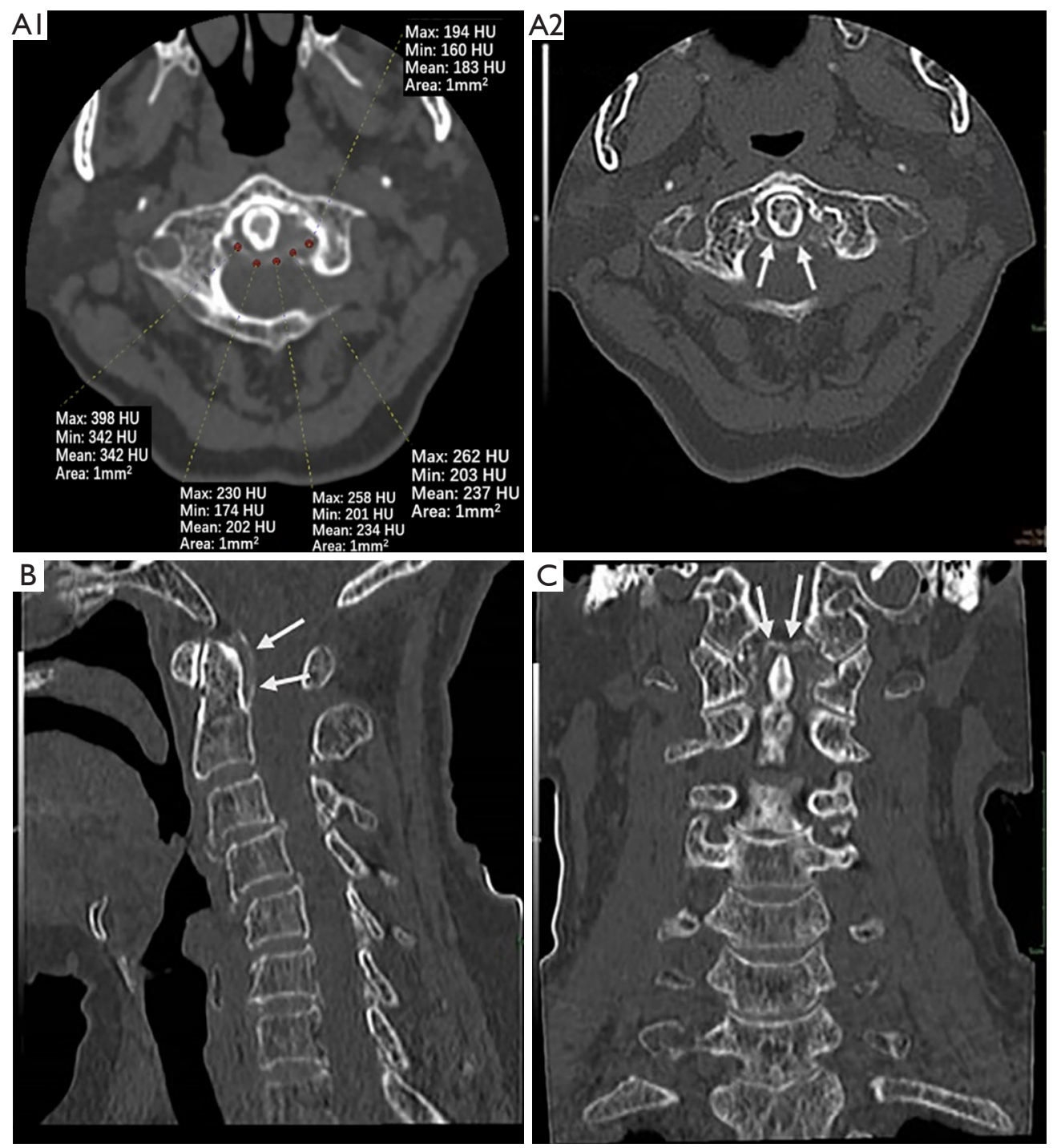

Figure 1 Case 1. Unenhanced cervical spinal CT images of a 74-year-old woman with CDS (window level: 500 HU; window width: 2,000 HU). Axial (A1, A2) CT images show lined-calcifications around the dense area (arrows), the mean CT number 183-342 HU (ROI area: $1.0 \mathrm{~mm}^{2}$ ) (A1). Sagittal (B) and coronal (C) MPR imaging (500 HU; 2,000 HU) shows lined-calcifications at the posterior and superior aspects of the dens (arrows). CT, computed tomography; CDS, crowned dens syndrome; ROI, region of interest; MPR, multi-planar reformatting.

physical examination findings at admission were as follows: temperature, $37.5^{\circ} \mathrm{C}$; pulse, 72 beats $/ \mathrm{min}$; respiration, 17 breaths/min; blood pressure, $125 / 75 \mathrm{mmHg}$; and the patient had the appearance of being in acute pain. The findings of laboratory examination at admission were as follows: WBC count, $10.52 \times 10^{9} / \mathrm{L}\left(4-10 \times 10^{9} / \mathrm{L}\right)$; ESR 34.7.6 mm/h (0-20 mm/h); CRP: $75.2 \mathrm{mg} / \mathrm{L}(0-6 \mathrm{mg} / \mathrm{L})$. An unenhanced CT of the cervical spine (Figure 2) revealed a similar resemblance to case 1: annular high-density around the dens. After 5 days of continuous treatment with glucocorticoids and NSAIDs, the clinical symptoms were gradually relieved. The laboratory examination results also became normal at this time. This patient was followed up for 2-months by telephone, without any recurrence.

\section{Discussion}

In 1985, CDS was first reported and described by Bouvet 

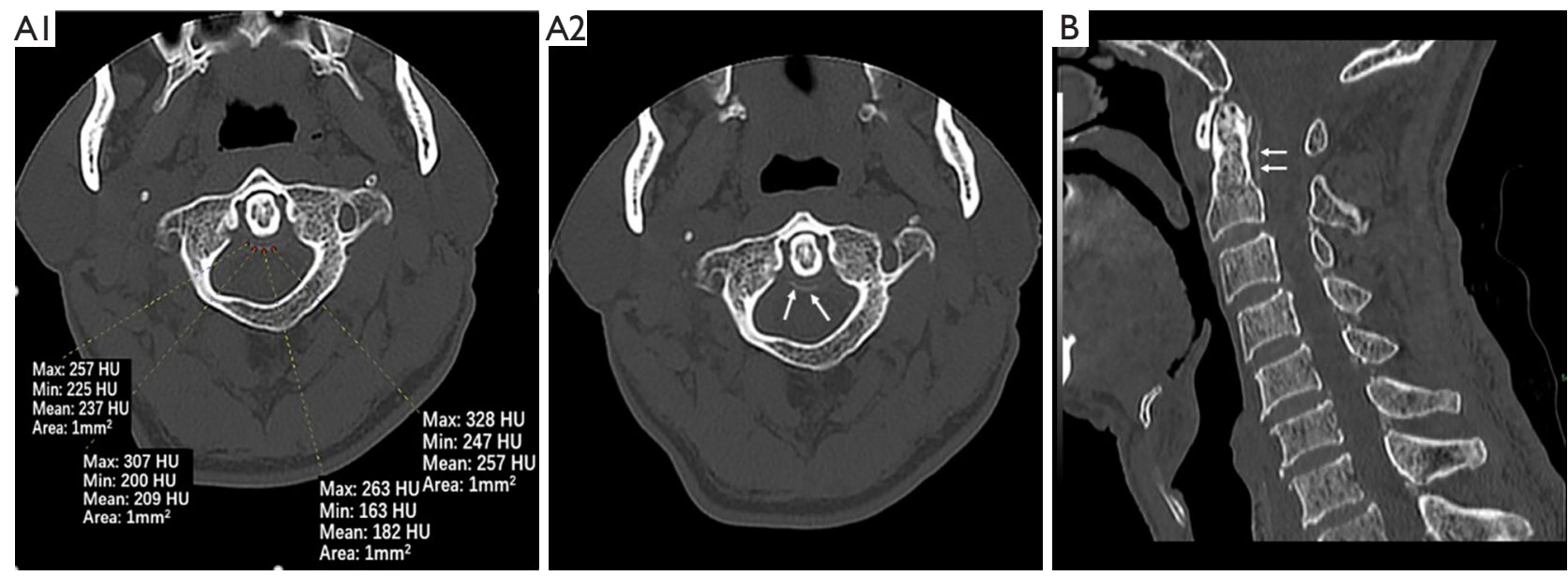

Figure 2 Case 2. The other patient with CDS, a 65-year-old man, in whom all CT findings resemble those of case 1. Axial (A1, A2) CT image unenhanced neck CT images (window level: $500 \mathrm{HU}$; window width: 2,000 HU) show lined-calcifications around the dense (A2 arrows), the mean CT number 182-257 HU (A1). Sagittal (B) MPR imaging (500 HU; 2,000 HU) shows lined-calcifications at the posterior and superior aspects of the dens (arrows). CT, computed tomography; CDS, crowned dens syndrome; MPR, multi-planar reformatting.

et al., and hundreds of cases have since been reported, most of which have been case reports or small series case reports. A rare condition, CDS is caused by calcium salt crystal deposition, especially CPPD (1), and a few cases have been reported as having been caused by HA deposition (2). Epidemiology shows that the disease is prevalent in elderly patients, especially in older women (3), and CPPD deposition occurs easily in elderly patients, while HA deposition is more common in younger age groups (40-70 years) (4,5). A review of the published literature revealed that most cases reported are over 60 years old. In this paper, the 2 patients were 75 and 65 years old, which was consistent with most reported cases. The exact incidence of CDS is still uncertain. It is reported that about $1.9 \%$ of outpatients with head and neck pain have CDS (6), and the incidence rate of articular chondrocalcinosis is $35-45 \%$ (7). It was reported that the cases were most commonly Japanese (53\%), followed by French (25\%), and Italian (16.6\%) (8). The risk factors of CPPD include age, osteoarthritis (OA), joint injury, metabolic disorders (hypophosphatemia, hyperparathyroidism, hemochromatosis, and hypomagnesemia), acute disease, and surgery $(9,10)$. Trauma, ischemia, endocrine disorders (diabetes, thyroid disease), and some genetic factors may play a role in HA deposition's pathophysiology (11).

Clinical manifestations are usually as follows $(8,12-14)$ : cervico-occipital pain (100\%), neck rigidity (98\%), and fever $(80.4 \%)$, which is called "triad syndrome" (15). In this group, the 2 patients had been treated for acute shoulder and neck pain, with varying degrees of the neck's restricted movement. One patient's temperature was slightly elevated. Because the pain is very similar to that of gout caused by elevated uric acid, CDS is also known as pseudogout. The pain sometimes radiates to the shoulder, occipital, or temporal region.

Additionally, most patients have fever symptoms. Therefore, it is easy for CDS to be misdiagnosed as meningitis, arthritis, polymyalgia rheumatica (PMR), and so on. However, meningitis usually presents as meningococcal irritation; CDS, on the other hand, presents with omnidirectional neck motion restriction (including rotation); arthritis is usually manifested as joint pain, commonly in the knee and hip, wrist, and interphalangeal joints; PMR may present as an abrupt onset of proximal pain in the neck and elevated markers of ESR and CRP, but more commonly as pain in the hip, shoulder girdle, and upper extremity, which can be so severe that patients may be unable to lift their arms, rise from a chair or even get out of bed without assistance (16). Moreover, PMR has a chronic onset, morning stiffness is not unusual, and musculoskeletal ultrasonography or magnetic resonance imaging (MRI) may show evidence of bursitis and synovitis of the shoulder, hip, and related structures. The laboratory tests of the 2 CDS patients showed that ESR, CRP, and WBC increased, suggesting that it was an inflammatory reaction 
$(8,15)$. Both of the cases had abnormal laboratory examination results.

In radiology, bone-window CT is the gold standard for the diagnosis of CDS and assists in ruling out fractures and primary or metastatic tumors (17), with a positive rate of about $97.1 \%$ (8). The most characteristic assessment feature is a high-density ring around the C1-C2 vertebral body, and the 2 patients in this group displayed this characteristic feature on CT. The calcium deposition of CDS sometimes involves the adjacent cruciate ligament and pterygoid ligament, which are shown to have a high density on CT. However, some scholars have surmised some literature and found that the CT value (202-258 HU) of a high-density transverse ligament of atlas attributed to $\mathrm{CDS}$ is higher than the CT value $(35-110 \mathrm{HU})$ of a normal transverse ligament of the atlas (8). The MRI is less sensitive than CT, but in some cases, bone marrow edema of adjacent bone and soft tissue can be seen, and enhancement can be seen after gadolinium contrast injection, a mechanism which may be similar to that of rheumatoid arthritis (18). Thus, it is suggested that symptomatic and asymptomatic CDS can be distinguished according to this sign (19). The MRI can also be used to evaluate the spinal cord more completely (5), and is useful for proving inflammation in patients with CDS (1).

The prognosis of CDS is excellent, and the clinical symptoms will be relieved or totally resolved within a few days or weeks. In a few severe patients, the excessive sediment volume may lead to spinal cord compression symptoms. In the acute stage, NSAIDs or steroid hormones are generally used to relieve symptoms. After several days of combined use of NSAIDs and glucocorticoids, the symptoms of the 2 patients in this group were significantly relieved, and the symptoms had almost disappeared after a week of medication. Some scholars $(6,20)$ have pointed out that compared with NSAIDs, the use of low- or mediumdose corticosteroids can significantly improve the level of CRP and neck and occipital pain scores in patients with CDS, and proposed the administration of low-dose corticosteroids (15-30 mg). Secondly, considering that sudden withdrawal of drugs is an independent factor for the recurrence of CDS, a gradual reduction is recommended before stopping the drug (20). It has also been reported that colchicine has a good effect on CDS, but its mechanism is still unclear (21).

In radiological work, we found that although several elderly patients were found to have an annular high density around the odontoid process, the patients do not classify as having "triad syndrome" symptoms, which confuses the process of diagnosing CDS. Some scholars have proposed that asymptomatic calcification around the odontoid process is very common $(22,23)$. After reviewing published reports, we speculate that there may be 3 reasons for this phenomenon: (I) With the increase of age, calcium deposition will become more obvious, leading to the calcification of ligaments around the odontoid process, not CDS. (II) Takahashi et al. (20) scored comprehensively according to the shape (point, sheet, ring), position (front and back left), and CT value of sediments around the odontoid process and highlighted that the comprehensive score was significantly correlated with the level of cyclic CRP. After treatment, both CRP and pain scores decreased significantly. Therefore, we speculate that acute neck pain in CDS patients may be related to the shape, location, and CT value. (III) The prognosis of CDS is excellent; it is a selflimiting disease and can only cause clinical symptoms when in the acute attack phase; so, this contingent of patients with abnormal CT findings does not manifest with clinical symptoms. Therefore, the imaging diagnosis of CDS needs to be closely combined with clinical and laboratory auxiliary examinations. Treatment for CDS is only necessary when the patient is experiencing an acute attack.

In summary, when CT examination reveals nodular, flake, or annular high-density around the odontoid process, the patient has had an acute onset of neck and occipital pain, and some laboratory examinations (such as CRP, ESR) have returned abnormal readings, the possibility of CDS is high, and confirmation of CDS could avoid further unnecessary examination and treatment. In treating an acute attack, low-dose glucocorticoids combined with NSAIDs should be the first choice for symptomatic treatment. Therefore, both clinical and imaging doctors should improve their understanding of CDS to avoid missed diagnoses, misdiagnoses, and improper treatment. Antibiotic treatment is required if it is misdiagnosed as meningitis, which is useless in CDS treatment and will prolong the condition. Also, a lumbar puncture and cerebrospinal fluid examination are required to confirm the diagnosis of meningitis, which is an invasive procedure with the risk of concomitant brain herniation (24). If misdiagnosed as cervical spondylosis, conservative treatment will not improve the patient's symptoms, and the surgical treatment option is invasive and represents overtreatment for patients with CDS. If CDS is incorrectly considered PMR, NSAIDs would not be administered, which plays a major role in improving symptoms in patients with CDS, while glucocorticoids will 
be used, but in much lower dosages. Also, PMR is treated with methotrexate, which is ineffective and can cause side effects in CDS patients.

\section{Acknowledgments}

We thank the AME English language editors J. Jones and J. Chapnick for providing English proofreading services. Funding: None.

\section{Footnote}

Conflicts of Interest: All authors have completed the ICMJE uniform disclosure form (available at http://dx.doi. org/10.21037/qims-20-1347). The authors have no conflicts of interest to declare.

Ethical Statement: The authors are accountable for all aspects of the work in ensuring that questions related to the accuracy or integrity of any part of the work are appropriately investigated and resolved. All procedures performed in studies involving human participants were in accordance with the ethical standards of the institutional and/or national research committee(s) and with the Helsinki Declaration (as revised in 2013). Written informed consent was obtained from the patient for publication of this study and any accompanying images. A copy of the written consent is available for review by the Editor-in-Chief of this journal.

Open Access Statement: This is an Open Access article distributed in accordance with the Creative Commons Attribution-NonCommercial-NoDerivs 4.0 International License (CC BY-NC-ND 4.0), which permits the noncommercial replication and distribution of the article with the strict proviso that no changes or edits are made and the original work is properly cited (including links to both the formal publication through the relevant DOI and the license). See: https://creativecommons.org/licenses/by-nc-nd/4.0/.

\section{References}

1. Inoue A, Kohno K, Ninomiya S, Tomita H, Iwata S, Ohue S, Kamogawa K, Okamoto K, Fukumoto S, Ichikawa H, Onoue S, Ozaki S, Okuda B. Usefulness of cervical computed tomography and magnetic resonance imaging for rapid diagnosis of crowned dens syndrome: A case report and review of the literature. Int J Surg Case Rep 2017;30:50-4.
2. Scutellari PN, Galeotti R, Leprotti S, Ridolfi M, Franciosi R, Antinolfi G. The crowned dens syndrome. Evaluation with CT imaging. Radiol Med 2007;112:195-207.

3. Haikal A, Everist BM, Jetanalin P, Maz M. Cervical CTDependent Diagnosis of Crowned Dens Syndrome in Calcium Pyrophosphate Dihydrate Crystal Deposition Disease. Am J Med 2020;133:e32-7.

4. Viana SL, Fernandes JL, De Araújo Coimbra PP, De Mendonça JL, Freitas FM, De Carvalho Barbosa Viana MA. The "crowned dens" revisited: imaging findings in calcium crystal deposition diseases around the odontoid. J Neuroimaging 2010;20:311-23.

5. Steinbach LS. Calcium pyrophosphate dihydrate and calcium hydroxyapatite crystal deposition diseases: imaging perspectives. Radiol Clin North Am 2004;42:185-205, vii.

6. Goto S, Umehara J, Aizawa T, Kokubun S. Crowned Dens syndrome. J Bone Joint Surg Am 2007;89:2732-6.

7. Roverano S, Ortiz AC, Ceccato F, Paira SO. Calcification of the transverse ligament of the atlas in chondrocalcinosis. J Clin Rheumatol 2010;16:7-9.

8. Oka A, Okazaki K, Takeno A, Kumanomido S, Kusunoki R, Sato S, Ishihara S, Kinoshita Y, Nishina M. Crowned Dens Syndrome: Report of Three Cases and a Review of the Literature. J Emerg Med 2015;49:e9-13.

9. McCarthy GM, Dunne A. Calcium crystal deposition diseases - beyond gout. Nat Rev Rheumatol 2018;14:592-602.

10. Ferrone C, Andracco R, Cimmino MA. Calcium pyrophosphate deposition disease: clinical manifestations. Reumatismo 2012;63:246-52.

11. Oliva F, Via AG, Maffulli N. Physiopathology of intratendinous calcific 1. deposition. BMC Med 2012;10:95.

12. Tang J, Li J, Wu C, Li Y, Lu Q, Xie W, Zhang T, Li X. Report of four cases of crowned dens syndrome: Clinical presentation, CT findings and treatment. Exp Ther Med 2020;20:3853-9.

13. Takahashi T, Minakata Y, Tamura M, Takasu T, Murakami M. A rare case of crowned dens syndrome mimicking aseptic meningitis. Case Rep Neurol 2013;5:40-6.

14. Lee GS, Kim RS, Park HK, Chang JC. Crowned dens syndrome: a case report and review of the literature. Korean J Spine 2014;11:15-7.

15. Aouba A, Vuillemin-Bodaghi V, Mutschler C, De Bandt $\mathrm{M}$. Crowned dens syndrome misdiagnosed as polymyalgia rheumatica, giant cell arteritis, meningitis or spondylitis: an analysis of eight cases. Rheumatology (Oxford) 2004;43:1508-12. 
16. Matteson EL, Dejaco C. Polymyalgia Rheumatica. Ann Intern Med 2017;166:ITC65-ITC80.

17. Koda R, Tsuchida Y, Yoshizawa K, Suzuki K, Kasai A, Takeda T, Kazama JJ, Narita I, Yoshida K. Crowned Dens Syndrome as an Initial Manifestation of Crystalline Deposition Disease. Intern Med 2015;54:2405-8.

18. Jimenez-Boj E, Nöbauer-Huhmann I, Hanslik-Schnabel B, Dorotka R, Wanivenhaus AH, Kainberger F, Trattnig S, Axmann R, Tsuji W, Hermann S, Smolen J, Schett G. Bone erosions and bone marrow edema as defined by magnetic resonance imaging reflect true bone marrow inflammation in rheumatoid arthritis. Arthritis Rheum 2007;56:1118-24.

19. Scheldeman L, Van Hoydonck M, Vanheste R, Theys T, Cypers G. Crowned dens syndrome: a neurologist's perspective. Acta Neurol Belg 2019;119:561-5.

20. Takahashi T, Tamura M, Takasu T, Kamei S. Clinical

Cite this article as: Qin X, Hu X, Wang Q, Zeng J, Chen J. A rare acute neck pain cause that can have misdiagnosis or missed diagnosis-crowned dens syndrome: description of two cases and a literature analysis. Quant Imaging Med Surg 2021;11(10):4491-4496. doi: 10.21037/qims-20-1347 and quantitative analysis of patients with crowned dens syndrome. J Neurol Sci 2017;376:52-59.

21. Duizer ML, Hermsen R, Te Boekhorst T, Janssen S. Acute headache and neck pain caused by crowned dens syndrome. Ned Tijdschr Geneeskd 2018;162:D2699.

22. Kobayashi T, Miyakoshi N, Konno N, Ishikawa Y, Noguchi H, Shimada Y. Age Related Prevalence of Periodontoid Calcification and Its Associations with Acute Cervical Pain. Asian Spine J 2018;12:1117-22.

23. Sano M, Yamashita S, Aiba T. The prevalence of calcification around odontoid process and the incidence of crowned dens syndrome in the neurosurgical ward: A single institution's analysis. Mod Rheumatol 2018;28:182-7.

24. Mount HR, Boyle SD. Aseptic and Bacterial Meningitis: Evaluation, Treatment, and Prevention. Am Fam Physician 2017;96:314-22. 